\title{
Myoblast differentiation of human mesenchymal stem cells on graphene oxide and electrospun graphene oxide-polymer composite fibrous meshes: importance of graphene oxide conductivity and dielectric constant on their biocompatibility
}

Citation for published version (APA):

Chaudhuri, B., Bhadra, D., Moroni, L., \& Pramanik, K. (2015). Myoblast differentiation of human mesenchymal stem cells on graphene oxide and electrospun graphene oxide-polymer composite fibrous meshes: importance of graphene oxide conductivity and dielectric constant on their biocompatibility. Biofabrication, 7(1), [015009]. https://doi.org/10.1088/1758-5090/7/1/015009

Document status and date:

Published: 01/03/2015

DOI:

10.1088/1758-5090/7/1/015009

Document Version:

Publisher's PDF, also known as Version of record

Document license:

Taverne

Please check the document version of this publication:

- A submitted manuscript is the version of the article upon submission and before peer-review. There can be important differences between the submitted version and the official published version of record. People interested in the research are advised to contact the author for the final version of the publication, or visit the DOI to the publisher's website.

- The final author version and the galley proof are versions of the publication after peer review.

- The final published version features the final layout of the paper including the volume, issue and page numbers.

Link to publication

\footnotetext{
General rights rights.

- You may freely distribute the URL identifying the publication in the public portal. please follow below link for the End User Agreement:

www.umlib.nl/taverne-license

Take down policy

If you believe that this document breaches copyright please contact us at:

repository@maastrichtuniversity.nl

providing details and we will investigate your claim.
}

Copyright and moral rights for the publications made accessible in the public portal are retained by the authors and/or other copyright owners and it is a condition of accessing publications that users recognise and abide by the legal requirements associated with these

- Users may download and print one copy of any publication from the public portal for the purpose of private study or research.

- You may not further distribute the material or use it for any profit-making activity or commercial gain

If the publication is distributed under the terms of Article $25 \mathrm{fa}$ of the Dutch Copyright Act, indicated by the "Taverne" license above,

Download date: 26 Apr. 2023 
PAPER

Myoblast differentiation of human mesenchymal stem cells on graphene oxide and electrospun graphene oxide-polymer composite fibrous meshes: importance of graphene oxide conductivity and dielectric constant on their biocompatibility

To cite this article: Biswadeep Chaudhuri et al 2015 Biofabrication 7015009

View the article online for updates and enhancements.

\section{Related content}

$$
\begin{aligned}
& \text { - The different fate of satellite cells on } \\
& \frac{\text { conductive composite electrospun }}{\text { nanofibers with graphene and graphene }} \\
& \hline \text { oxide nanosheets } \\
& \text { Matin Mahmoudifard, Masoud Soleimani, } \\
& \text { Shadie Hatamie et al. } \\
& \text { - Graphene oxide nanoflakes incorporated } \\
& \underline{\text { gelatin-hydroxyapatite scaffolds enhance }} \\
& \text { osteogenic differentiation of human } \\
& \text { mesenchymal stem cells } \\
& \text { Manitha Nair, D Nancy, Amit G Krishnan et } \\
& \text { al. } \\
& \text { - Development of novel silk fibroin/polyvinyl } \\
& \frac{\text { alcohol/sol-gel bioactive glass composite }}{\text { matrix by modified layer by laver }} \\
& \frac{\text { electrospinning method for bone tissue }}{\text { construct generation }} \\
& \text { B N Singh and K Pramanik }
\end{aligned}
$$

\section{Recent citations
The effect of adding reduced graphene oxide to electrospun polycaprolactone scaffolds on MG-63 cells activity Parisa Haji Mohammadi Gohari et al
- Biohybrid oxidized alginate/myocardial extracellular matrix injectable hydrogels with improved electromechanical properties for cardiac tissue engineering Ali Mousavi et al
Bioactive Electrospun Fibers: Fabrication Strategies and a Critical Review of Surface-Sensitive Characterization and Quantification
Mehmet Berat Taskin et al

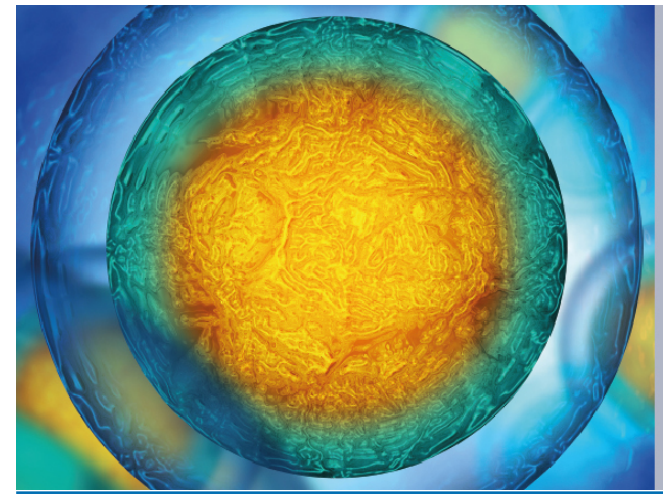

Biophysical Society $\quad$ IOP | ebookS

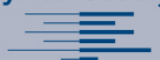

Your publishing choice in all areas of biophysics research.

Start exploring the collection-download the first chapter of every title for free. 


\title{
Biofabrication
}

\section{PAPER}

CrossMark

\section{Myoblast differentiation of human mesenchymal stem cells on}

RECEIVED
11 August 2014

REVISED

26 December 2014

ACCEPTED FOR PUBLICATION

21 January 2015

PUBLISHED

18 February 2015 graphene oxide and electrospun graphene oxide-polymer composite fibrous meshes: importance of graphene oxide conductivity and dielectric constant on their biocompatibility

\author{
Biswadeep Chaudhuri ${ }^{1}$, Debabrata Bhadra ${ }^{2}$, Lorenzo Moroni ${ }^{3,4}$ and Krishna Pramanik ${ }^{1}$ \\ 1 Department of Biotechnology and Medical Engineering, National Institute of Technology, Rourkela, Odisha-769008, India \\ 2 Department of Solid State Physics, Indian Association for the Cultivation of Science, Kolkata-700032, India \\ 3 University of Twente, Tissue Regeneration Department, Drienerlolaan 5, 7522NB Enschede, The Netherlands \\ 4 Maastricht University, MERLN Institute for Technology-Inspired Regenerative Medicine, Complex Tissue Regeneration Department, P. \\ Debyelaan 25, 6229 HX Maastricht, The Netherlands \\ E-mail: mondalkp@gmail.com (Krishna Pramanik)
}

Keywords: mesenchymal stem cells, myogenic differentiation, graphene oxide (GO), GO-polymer composites, tissue engineering

Supplementary material for this article is available online

\begin{abstract}
Recently graphene and graphene based composites are emerging as better materials to fabricate scaffolds. Addition of graphene oxide (GO) nanoplatelets (GOnPs) in bioactive polymers was found to enhance its conductivity $(\sigma)$ and, dielectric permittivity $(\varepsilon)$ along with biocompatibility. In this paper, human cord blood derived mesenchymal stem cells (CB-hMSCs) were differentiated to skeletal muscle cells (hSkMCs) on spin coated thin GO sheets composed of GOnPs and on electrospun fibrous meshes of GO-PCL (poly-caprolactone) composite. Both substrates exhibited excellent myoblast differentiations and promoted self-alignedmyotubesformation similar to natural orientation. $\sigma, \varepsilon$, microstructural and vibration spectroscopic studies were carried out for the characterizations of GO sheet and the composite scaffolds. Significantly enhanced values of both $\sigma$ and $\varepsilon$ of the GO-PCL composite were considered to provide favourable cues for the formation of superior multinucleated myotubes on the electrospun meshes compared to those on thin GO sheets. The present results demonstrated that both substrates might be used as potential candidates for CB-hMSCs differentiation and proliferation for human skeletal muscle tissue regeneration.
\end{abstract}

\section{Introduction}

One of the current trends in tissue engineering (TE) is to fabricate excellent biocompatible substrates, which should offer appropriate guiding cues for the growth and proliferation of specific tissue types [1]. Materials for such scaffolds should have suitable mechanical properties, chemical and biological compatibility and degrade in an appropriate time window [2-4]. During the last couple of decades many electrospun nanofibrous scaffolds [5-11] and carbon based nanomaterials (e.g. carbon nanotubes, nanodiamonds or graphene) [12-16] have been widely investigated for different clinical and TE applications. Recently, graphene and its derivatives (figure 1(a)) have drawn special attention as novel nanomaterials with great potential in applications and utilizations such as photonics and optoelectronics [17], sensors [18, 19], biomedical as well as TE [13, 20-26], because of their extraordinary physicochemical properties and favourable bioactivity [16]. These properties further extended their intensive applications for the differentiation of human neural stem cells [21], osteogenic differentiation of human stem cells [24], drug delivery $[25,26]$ and also in photothermal cancer therapy $[10,23]$. An injectable graphene/hydrogel-based gene delivery system has been developed for vasculogenesis and cardiac tissue repair [27]. The antibacterial property $[28,29]$, anti-inflammatory effects [30] and biocompatibility [16] of graphene and graphene oxide nanoplatelets (GOnPs) were also tested with mammalian cells $[8,13,21,31]$ by different research groups. 
Induced pluripotent stem cells (iPSCs) cultured on graphene oxide (GO) surface were found to adhere and proliferate even at a faster rate than graphene [32]. Graphene showed controlled and accelerated osteogenic differentiation of human mesenchymal stemcells $[13,33]$. All these favorable results revealed superior biocompatibility of graphene based materials for tissue culture and other biomedical applications compared to many bioactive polymer scaffolds $[7,9,34]$. Moreover, in contrast to carbon nanotubes and nanodiamond, GOnPs can be more easily prepared in pure form [35]. Importantly, the biocompatibility of graphene and graphene derivatives appear to be unexpectedly related to their different physical properties namely electrical conductivity $(\sigma)$, surface charge $(Q)$, dielectric permittivity or dielectric constant $(\varepsilon)$ and piezoelectricity (piezoelectric (PE) coefficient $d_{33}$, related to $Q$ and $\varepsilon$ ) similar to many other scaffolds [36-45]. The derivatives of conducting graphene, especially GO or reduced graphene oxides (rGOs) possess lower $\sigma$ and higher $\varepsilon$ values depending on $\mathrm{C} / \mathrm{O}$ ratios.

Many conducting polymer scaffolds were reported to be favourable for cell growth and differentiation [7, 8, 46-49]. In fact, insulating scaffolds limit electrical signal propagation throughout the engineered cardiac tissues $[37,38]$. To date, conducting polymers like polypyrrole and polyaniline are widely investigated for biomedical applications as scaffolds or cell culture substrates [7, 9, 48, 49]. Myoblast differentiation is also stimulated by electrically conductive sub-micron fibers [39]. In case of TE, the cells growth was improved in presence of electroresponsive materials $[37,50]$. Insulating polycaprolactone (PCL) blended with conducting nanofibers formed excellent conducting biocompatible composites which enhanced cells proliferation [51]. However, the filler used must be biocompatible and should have low percolation threshold for conductivity/dielectric permittivity. Higher filler content, on the other side could also decrease the mechanical properties of the scaffold. GO is biocompatible and GO-polymer composite (figure 1(b)) also showed low percolating threshold for conductivity and dielectric permittivity $[52,53]$ with low GO content. Therefore, GO is a promising filler for the fabrication of biocompatible nanocomposite scaffolds, which is known to enhance differentiation of human neural stem cells [21] and can be cleared by renal excretion, phagocytosis and other means [54, 55]. Enzymatic degradation of graphene/PCL for TE was studied by Murry and co-workers [56] exploring the effects of graphene addition on the degradation rates of the correspondent nanocomposite scaffolds. In addition to electrical and topographical cues, PE (related to $\varepsilon$ ) responses of scaffold materials might also control the addition and differentiation of specific cell types [5760]. For instance, dielectric and PE properties of hydroxyapatite are important for bone growth $[59,60]$. Electrically conducting scaffolds were also reported to be favourable to stimulate muscle [39], bone [60] and cardiac tissues [48]. Low conducting high dielectric [52] GO possesses surface charge $[44,61,62]$ and also PE properties [64] which are also stimulants for cells growth. Surface charge and dielectric constant are associated with the PE property (PE coefficient $d_{33}$ is related to dielectric constant [65]) of oxides and polymers scaffold materials [57, 59, 64]. PE and dielectric properties are the unique universal properties of living tissues, and may play a significant role in several physiological phenomena [43, 58, 64-68]. Therefore, $\sigma, \varepsilon, Q$ and PE properties, which vary with the oxidation of graphene, might appear to be relevant for the biocompatibility of graphene based materials for different biomedical and tissue regeneration applications.

A few detailed studies on the relationship between human stem cell and graphene have drawn a tremendous impetus in the field of different TE applications $[21,27,33]$. These investigations were carried out mainly with bone marrow derived mesenchymal stem cells, iPSCs and neural cells. Although mouse myoblast proliferation on rGO deposited modified glass substrate was reported [22], no study focussed on the proliferation and differentiation of human mesenchymal stem cells to skeletal muscle cells on GO sheet or GO-polymer fibrous scaffold. These studies are important for exploring the possibility of fabricating different GOpolymer based biocompatible conducting electrospun scaffolds for the repair and regeneration of skeletal muscle and other tissues using human stem cells.

In the present studies we have utilized umbilical cord blood (UCB) derived multipotent mesenchymal stem cells (CB-hMSCs) for direct differentiation to skeletal muscle cells (hSkMCs)on spin coated dielectric and semiconducting thin GO sheets as well as on electrospun GO-PCL fibrous meshes with enhanced $\sigma$ and $\varepsilon$ (compared to PCL alone). We showed the differentiation of CB-hMSCs to hSkMCs and the formation of myotubes on these scaffolds. To the best of our knowledge, myoblast differentiation of CB-hMSCs on GO sheet and GO-polymer fibrous meshes had not been carried out earlier. Recently, proliferation of cryopreserved CB-hMSCs on silk nanofibers has been reported [69] and the possible size-dependent toxicity of GOnPs on CB-hMSCs [70] has been studied showing noadverse effects. We have also measured $\sigma$ and $\varepsilon$ values of GO sheet and GO-polymer composite meshes. Conductivity and surface charge of GO sheet provided important cues for their excellent biocompatibility and cell scaffold construct. Our results demonstrated these scaffolds as potential substrates for future myoblast regeneration and biomedical application.

\section{Experimental}

\subsection{Materials and methods}

PCL of mol. wt. 90 000, chloroform, acetic acid and $\mathrm{N}, \mathrm{N}$-dimethyleformamide (DMF) were purchased 
from Merck, Germany. Skeletal muscle growth media and skeletal muscle differentiation media (Promocell, Germany); insulin like growth factor 1 (IGF-1) (Invitrogen, USA), fetal bovine serum (FBS), horse serum, antibiotic-antimycotic solution, phosphate buffer saline (PBS) solution (GIBCO, USA); paraformaldehyde, dimethyl sulfoxide (DMSO) (Sigma Aldrich, USA); all primary and secondary antibodies (Abcam, United Kingdom);WST-8 [2-(2-methoxy-4nitrophenyl)-3-(4-nitrophenyl)-5-(2,4-disulfophenyl)-2H-tetrazolium, monosodium salt], collagen type-1 (rat tail) and fluorescein isothiocyanate (FITC)-phalloidin (Sigma Aldrich, USA) were purchased and used as received.

\subsection{Preparation of GO sheet and GO-PCL meshes} GOnPs were synthesized from graphite powder similarly to our previous work [19, 52] following the modified Hummers method [71]. In brief, graphite $(2 \mathrm{~g})$, sodium nitrate $(1 \mathrm{~g})$ and $\mathrm{H}_{2} \mathrm{SO}_{4}$ were added to a $250 \mathrm{ml}$ flask kept at $0{ }^{\circ} \mathrm{C}$. Concentrated $\mathrm{H}_{2} \mathrm{SO}_{4}$ $(50 \mathrm{~mL})$ was then poured slowly while stirring keeping temperature below $5^{\circ} \mathrm{C}$. The mixture was then stirred for $30 \mathrm{~min}$ and $0.3 \mathrm{~g}$ of $\mathrm{KMnO}_{4}$ powder was added while the system was maintained at $35^{\circ} \mathrm{C}$ for $30 \mathrm{~min}$. The mixture was further diluted with warm water and treated with $\mathrm{H}_{2} \mathrm{O}_{2}$ to remove residual $\mathrm{KMnO}_{4}$ until bubbling disappeared. The resulting solution was centrifuged at $6500 \mathrm{rpm}$ for $45 \mathrm{~min}$ for three times and $1 \mathrm{~N} \mathrm{NaOH}$ was added to adjust the $\mathrm{pH}$ value of the solution to 7.4 approximately. The solid mass thus synthesized was washed with de-ionized water to obtain pure GOnPs used to make thin GO sheet by spin coating and GO-PCL meshes by electrospinning techniques. Spin coated thin GO sheets $(20-60 \mu \mathrm{m}$ thickness depending on GO concentration in DMF) on cleaned glass plates and Teflon sheets were prepared from DMF solutions of GOnPs by sonicating the mixture for $2 \mathrm{~h}$ to uniformly disperse GO nanoparticles. The dried thin GO sheets were peeled off the glass/Teflon substrates which were used for cell culture after vacuum drying at around $37^{\circ} \mathrm{C}$ for about $3 \mathrm{~h}$. Electrospun fibrous meshes were prepared from the GO-PCL-DMF solution. To make composite solution, PCL ( $1 \mathrm{~g}$ in $25 \mathrm{ml}$ DMF solution) and GO $\left(20 \mu \mathrm{g} \mathrm{ml}^{-1}\right.$ PCL/DMF solution) were mixed and sonicated for 45-50 min. The final colloidal solution loaded into a $10 \mathrm{~mL}$ plastic syringe with a stainlesssteel needle (diameter $\sim 0.65 \mathrm{~mm}$ ) was used for making electrospun scaffolds using electrospinning (PICO ESPIN, India). The needle for electrospinning was connected to a high voltage supply $(\sim 20 \mathrm{kV})$ and the flow rate of the solution was adjusted to $1.5 \mathrm{ml} \mathrm{h}^{-1}$. The fibres were collected on a rotary drum wrapped with aluminium foil placed at a distance of $12 \mathrm{~cm}$ from the needle tip. Electrospun PCL and collagen $\left(0.10 \mathrm{~g} \mathrm{ml}^{-1}\right.$ acetic acid $)$ meshes were also prepared using similar technique. Collagen $\left(0.10 \mathrm{~g} \mathrm{ml}^{-1}\right.$ acetic acid solution) meshes for control were prepared using similar technique as mentioned above with collecting foil at adistance of $\sim 10 \mathrm{~cm}$ and flow rate $1.2 \mathrm{ml} \mathrm{h}^{-1}$ ). Collagen type- 1 coating on glass was applied for better cellular attachment and growth. For this, collagen solution ( $1 \mathrm{mg} \mathrm{ml}^{-1}$ of $0.1 \mathrm{M}$ acetic acid solution) was spread over sterile glass cover slips and incubated for $1 \mathrm{~h}$ at room temperature (RT). The remaining solution was removed and the glass cover slips were rinsed 3 times with PBS solution. Plates were then air dried and UV (wavelength $\sim 254 \mathrm{~nm}$ and power $15 \mathrm{~W}$ ) sterilization was performed for $4 \mathrm{~h}$ before culturing cells on them.

\subsection{Physicochemical characterization of GO sheet and GO-PCL meshes}

Thin GO sheet and GO-PCL composite meshes were characterized by $\mathrm{x}$-ray diffraction (XRD) (Philips Shiffert 3710 diffractometer using $\mathrm{Cu}-\mathrm{K}_{\alpha}$ radiation source) analysis, scanning electron microscopy (SEM: JEOL JSM 6400), field emission scanning electron microscope (FESEM:Model JEM-2012, JEOL) and high resolution transmission electron microspore (HRTEM: Model JEM-2010, JEOL) studies. Raman spectroscopy (HORIBA JOBIN Yuon: exciting wavelength $514 \mathrm{~nm}$ with argon ion laser), ultraviolet and visible (UV) (300-800 nm) and Fourier transform infrared (FTIR: Perkin-Elmer spectrum 100 FTIR spectrometer with a $4 \mathrm{~cm}^{-1}$ resolution) spectroscopic studies were also carried out for characterizing GO and GO-PCL composite. Water contact angle (CA) measurements against distilled water were performed using a sessile drop method (DAS100S: KRUSS $\mathrm{GMbH}$, Germany). The advancing (wetting $\mathrm{CA}_{\mathrm{w}}$ ) and receding (dewetting $\mathrm{CA}_{\mathrm{dw}}$ ) CAs were measured at $\mathrm{RT}$ at different locations for the GO sheets. Mechanical characterization of the GO sheet was performed by uniaxial tensile testing. GO sheets were carefully cut into rectangular stripes $(15 \times 30 \mathrm{~mm})$ and loaded with an Instron 3369 tensile strength measuring system. A segment of electrospun meshes $(10 \times 25 \mathrm{~mm})$ was fixed at the cut ends for the axial testing $(n=5)$. Frequency dependent conductivity and dielectric constant $(\varepsilon)$ of the GO sheet and electrospun meshes were measured using impedance analyser (HP Model 4194A) similarly to our previous work [52, 72]. For electrical measurements electrodes on the surfaces of the samples were made by high quality silver paint which was dried in vacuum. To estimate in vitro stability and biodegradation of the GO sheets, we also studied $\sigma$ and $\varepsilon$ values of GO sheet and composite meshes after immersion in PBS solution for 7 days at ambient temperature. After immersion, both the samples were removed from the soaked solution washed with deionised water, and dried in a vacuum chamber to remove moisture, before electrical measurements. 


\section{Cell culture}

The mesenchymal stem cells, CB-hMSCs, used for differentiation to skeletal muscle cells on the GO sheet and GO-PCL mesh were isolated from human UCB similarly to previous method $[69,73]$. UCB was collected from ISPAT General Hospital, Rourkela with patient's consent. All procedures were approved by the National Institutional Ethical Committee.

\subsection{Cell seeding, myoblast differentiation and myotubes formation}

UCB derived CB-hMSCs $\left(5 \times 10^{3}\right.$ cells/well $)$ were directly seeded on the thin film like GO sheet $(\sim 30 \mu \mathrm{m}$ thick) and GO-PCL mesh (areas $\sim 45 \mathrm{~mm}^{2}$ ) as well as on electrospun collagen fibrous meshes and collagen coated glass as controls(hereafter referred to as controls) in a 12 well plate and cultured with skeletal muscle differentiation media $(90 \mathrm{v} / \mathrm{v} \%)$ supplemented with FBS $(10 \mathrm{v} / \mathrm{v} \%)$ and $100 \mathrm{x}$ antibiotic-antimycotic solution ( $1 \mathrm{v} / \mathrm{v} \%$ approximately), and incubated at $37^{\circ} \mathrm{C}$ and $5 \% \mathrm{CO}_{2}$ atmospheric condition. In addition, insulin like IGF-1 was added $\left(5 \mathrm{ng} \mathrm{m}^{-1}\right)$ to enhance the myogenic differentiation process. After $12-15$ days of culture, cells morphology was found to change towards bipolar skeletal myoblasts (hSkMCs). Low serum ( $2 \%$ horse serum) media was introduced to enhance myoblast fusion and formation of selfaligned myotubes.

\subsection{Immunostaining analysis}

For immunostaining analysis, hSkMCs grown after 5 days of culture on different substrates (i.e. collagen and glass controls, GO sheets and GO-PCL meshes) were analysed for the expression of myogenin, an early myogenic differentiation marker. Briefly, to detect myogenin, cells werefixed and incubated with primary antibody $(1: 100)$ at $4{ }^{\circ} \mathrm{C}$ overnight and after washed with PBS, again incubated with secondary antibody DyLight 488-conjugated goat anti-mouse IgG (1:100) at RT for $1 \mathrm{~h}$. before viewing. On 11 days of culture, cells were analysed for further expression of muscle specific antigens such as myosin heavy chain (MHC) and dystrophin. Cells were fixed with $4 \%$ paraformaldehyde, permeabilized with $0.1 \%$ Triton X-100, and then incubated in goat polyclonal anti-MHC (1:100) and rabbit polyclonal anti-dystrophin (1:100) as primary antibodies for $1 \mathrm{~h}$. Next, after washing with PBS, a FITC conjugate rabbit anti-goat secondary antibody (1:500) was used to detect MHC, while Texas Red conjugated goat anti-rabbit secondary antibody (1:150) was also employed to detect dystrophin. The samples stained without primary antibody served as negative controls. Nuclei were counterstained with 4',6-diamidino-2-phenylindole (DAPI). Substrates with cells were then mounted for fluorescence microscopic studies using a Zeiss Axivert 40 CFL fluorescence microscope.

\subsection{Fluorescence-activated cell sorter (FACS) analysis}

The skeletal muscle cells adhered onto the GO sheet, GO-PCL meshes and controls were trypsinized and FACS analysis was performed to verify the expression of skeletal muscle differentiation markers like CD56 and desmin. For all antibodies, $5 \times 10^{5}$ cells were incubated in $100 \mathrm{ml}$ of PBS containing $1 \% \mathrm{FBS}$ and the dilution of primary antibodies ranged from 1:15 to 1:100. The cells after being incubated with primary antibody on ice for $30 \mathrm{~min}$, were washed with $1 \%$ FBS in PBS, re-suspended in $100 \mathrm{ml}$ of FITC-labelled secondary antibody, diluted 1:100 in 1\% FBS in PBS and incubated again for $30 \mathrm{~min}$ on ice. Finally, the cells were washed with PBS containing $1 \%$ FBS prior to resuspension in PBS with 1\% FBS for FACS analysis. Isotype-matching immunoglobulin (IgG) and FITClabelled secondary antibody were used to determine nonspecific signals. FACS analyses were performed with a BD LSR Fortessa (San Jose, CA, USA) equipped with an air cooled argon laser. FACS data were analysed by FCS Express software.

\subsection{Cells adhesion from SEM and FESEM analysis}

Cells adhesion on the different substrates was studied by SEM/FESEM analysis. After 11 days of culture, the cells seeded on all the substrates were carefully washed twice with PBS, fixed with 2.5\% glutaraldehyde for $4 \mathrm{~h}$ and then dehydrated through a gradient series of ethanol from 70 to $100 \%$. All the said substrates were then carefully dried using a vacuum desiccator to make them moisture free prior to SEM or FESEM analysis.

\subsection{Cell morphology}

The morphology of skeletal muscle cells were analysed using cytoskeleton staining after 3 days of culture. Cells were fixed with $4 \%$ paraformaldehyde, permeabilized with $0.1 \%$ Triton X-100 and stained with FITC-phalloidin. Nuclei were counterstained with DAPI. The actin filaments and nuclei were observed using a Zeiss Axivert 40 CFL fluorescence microscope.

\subsection{Cell viability and proliferation}

The vastly used methylthiazolyldiphenyl-tetrazolium bromide (MTT) assay which is a typical nontoxicity assay may not correctly predict the toxicity of GO because of the mild reaction of MTT salt with GO resulting in an incorrect positive signal. Therefore, we used, alternatively, a water soluble tetrazolium salt (WST-8) assay [29]. Cell viability and proliferation on GO/PCL composite meshes, thin GO sheet and controls were measured by water-soluble tetrazolium salt (WST-8) assay after 3, 7 and 11 days of cell seeding in 96 well culture plate. Ten $\mu \mathrm{l}$ of cell proliferation reagent (WST-8) was added into each well containing sample with $100 \mu \mathrm{l}$ of culture medium and incubated for $4 \mathrm{~h}$ at $37^{\circ} \mathrm{C}$. Absorbance (OD) of the solution was then measured at $450 \mathrm{~nm}$ by a microplate reader 


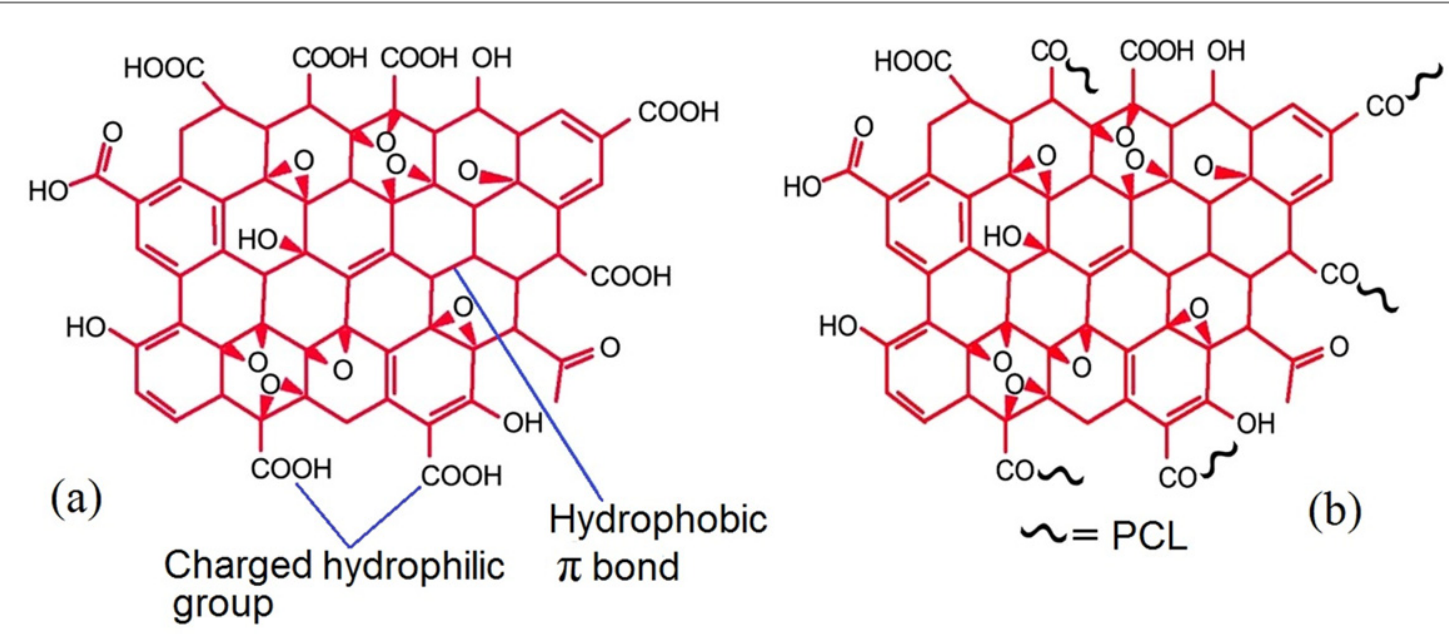

Figure 1. Schematic presentation of the honeycomb structure of (a) graphene oxide (GO) and (b) GO-polymer (PCL) composite suitable for biological interaction.

(Varioskan Flash, Thermo Scientific). The cells seeded on collagen scaffolds were evaluated as control. WST8 was reduced by dehydrogenase activities of living cells that give rise yellow-colour formazan dye. The amount of formazan dye generated (by the activities of dehydrogenases) was directly proportional to the number of living cells.

\subsection{Statistical analysis}

All data were presented as mean \pm standard deviation. Single factor analysis of variance (ANOVA) was carried out to compare the mean of different data sets and a value of $p \leqslant 0.05$ was considered significant.

\section{Results and discussion}

\subsection{Physicochemical properties}

Figure 2(a) showed the GO-DMF-PCL colloidal solution used for making GO-PCL meshes, a solution cast flexible GO sheet and a spin coated thin GO sheet on a glass plate. XRD patterns of GO sheet, GO-PCL and PCL meshes are presented in figures 2(b) and (c). XRD of GO sheet showed the characteristic GO peak appearing at $2 \theta=11.1^{\circ}$, corresponding to a lattice dspacing of $0.78 \mathrm{~nm}$. For the GO-PCL meshes, an XRD peak appeared at $21.65^{\circ}$ representing the crystalline phase of the polymer [74]. The XRD pattern of GOPCL indicated only PCL diffraction peak with no peak for GO around $2 \theta=11.1^{\circ}$. Similar absence of GO peak was also reported earlier in case of GO-polyvinyl alcohol (PVA) composite [52]. These results demonstrated the disappearance of the regular and periodic structure of GO, the formation of fully exfoliated structures, and the homogeneous distribution of GOnPs in thepolymer matrix [75]. As revealed from these data, well-dispersed GOnPs acted as nucleating agents and thus the crystallinity of the composites was also improved. The SEM image of a GO sheet surface shown in figure S1(a) (in supplementary information) indicated uniformly rough surface morphology. Inset of figure S1(a) also presented FESEM micrograph showing the surface morphology of thin GO sheet which indicated wrinkles stacked in multiple GOnPs layers. It was reported [74] that such surface morphology might favour cell adhesion and growth. Figure S1(b), in supplementary information, represented the SEM micrograph of the electrospun fibrous meshes and the selected area electron diffraction pattern (inset of S1(b)) indicating the presence of sharp diffraction spot of nanocrystalline GO in GOPCL mesh (average fibre diameter of $390 \pm 125 \mathrm{~nm}$ ). Raman spectra of GO sheet as shown in figure 3(a), indicated the characteristic feature of GO peaks at frequencies around 1345 and $1597 \mathrm{~cm}^{-1}$, respectively, for the $G$ and $D$ band usually assigned to the $E_{2 g}$ phonon of $\mathrm{Csp}^{2}$ atoms and a phonon breathing mode of symmetry $A_{1 \mathrm{~g}}$. The presence of GO peaks was also observed from the GO-PCL Raman spectra (inset of figure 3(a)). Characteristic frequencies corresponding to the well-studied $\mathrm{G}$ and $\mathrm{D}$ bands agreed with the literature values [76, 77], also indicating little lattice distortion of the GO nanostructure. The intensity ratio $I_{\mathrm{D}} / I_{\mathrm{G}}$ of the two peaks was widely used as characterizing the defect quantity within the GO materials $[78,79]$. By controlling the amount of defect quantity, the electronic and mechanical properties of the GO sheets might also be tuned [80]. In single or multilayer graphene, Raman spectra showed 2D characteristic peak around $2700 \mathrm{~cm}^{-1}$ [81-83]. The observed D and $\mathrm{G}$ bands were comparable with those of previously reported values for GO [84-88]. The D band was reported to be associated with the structural imperfections created by attachment of hydroxyl and epoxide groups on the carbon basal plane [88]. The G band corresponds to the ordered $\mathrm{sp}^{2}$ bonded carbon. GO conduction was also reported to occur through $\mathrm{sp} 2$ 

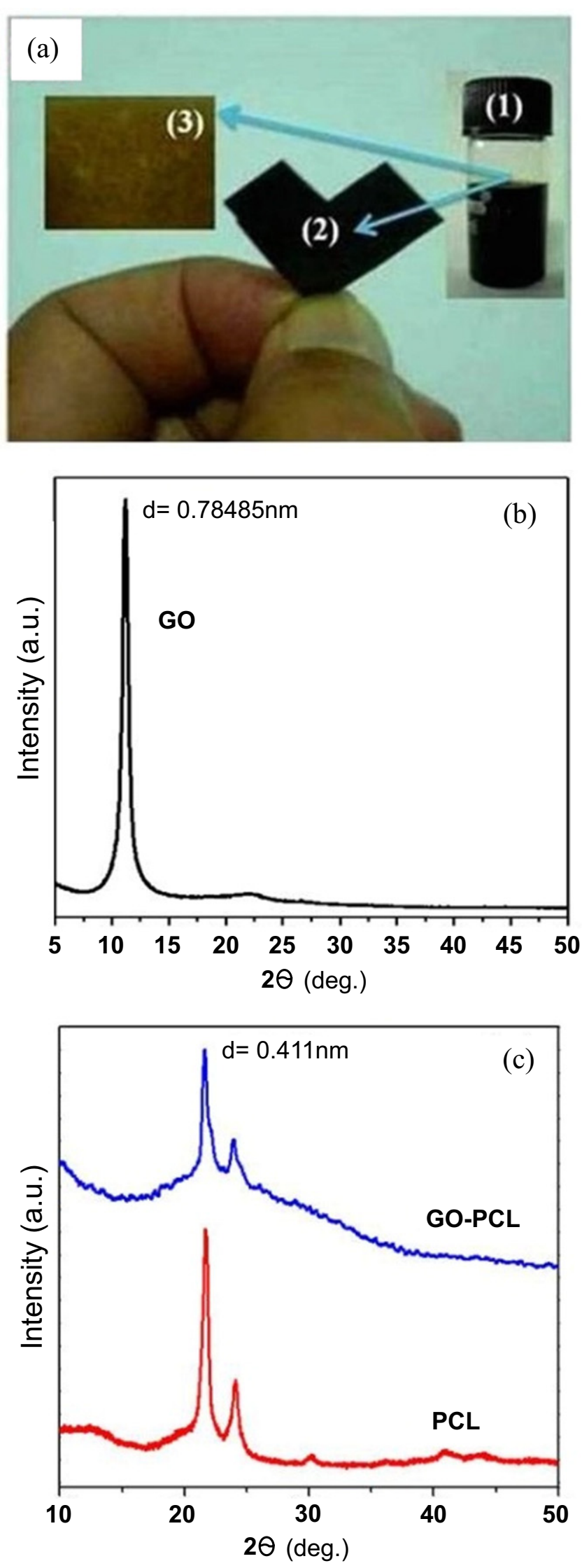

Figure 2. (a) Well dispersed GO-DMF--PCL solution (1), free standing bendable thin GO sheet prepared by solution casting (2) and spin coated thin GO sheet on cover glass (3) produced from GO-DMF solution. X-ray diffraction patterns of GO sheet (b), GO-PCL and PCL meshes (c). 

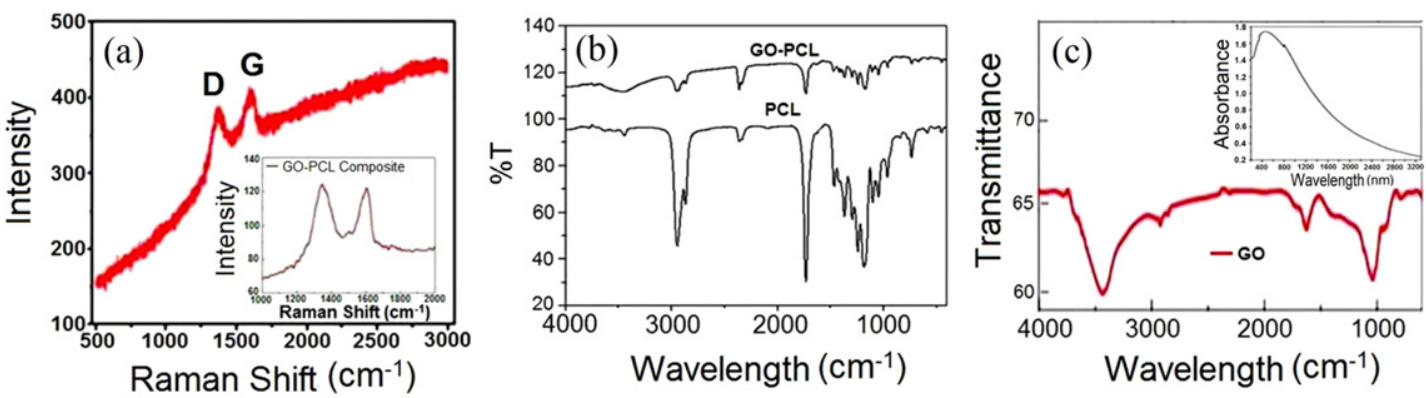

Figure 3. (a) Raman spectra of GO sheets and GO-PCL meshes (inset). (b) FTIR spectra of PCL and GO-PCL meshes. (c) FTIR spectra of GO sheets and UV spectra of GO-PCL in solution (inset).

regions via Klein tunnelling [89]. In figure 3(a), the 2D band corresponding to $2700 \mathrm{~cm}^{-1}$ was hardly observed, which indicated absence or negligible presenceof pure conducting graphene in the GO sheet of our present investigation. FTIR spectra (figure $3(\mathrm{~b})$ ) of GO-PCL showed absorption bands at $1727 \mathrm{~cm}^{-1}$ indicating carbonyl stretching. The bands appearing at $1295 \mathrm{~cm}^{-1}$ and $1240 \mathrm{~cm}^{1}$ represented the $\mathrm{C}-\mathrm{O}$ and C$\mathrm{C}$ stretching bonds. The bands at 1239 and $1175 \mathrm{~cm}^{-1}$ were comparable with the asymmetric $\mathrm{C}-\mathrm{O}-\mathrm{C}$ stretching bonds indicating characteristic absorption [90] of PCL. The FTIR spectrum of GO (figure 3(c)) indicated an intense band at $3438 \mathrm{~cm}^{-1}$ which was attributed to stretching of the $\mathrm{O}-\mathrm{H}$ band of $\mathrm{CO}-\mathrm{H}$. The band at $1639 \mathrm{~cm}^{-1}$ was associated with stretching of the $\mathrm{C}=\mathrm{O}$ bond of carbonyl groups. Deformation of the $\mathrm{C}-\mathrm{O}$ band was observed at the band present at $1017 \mathrm{~cm}^{-1}$. From FTIR spectroscopy, evidences of different types of oxygen functionalities on GO were exhibited. The UV spectrum of GO exhibited maximum at $371 \mathrm{~nm}$, characteristic feature of the $\pi-\pi$ transition of aromatic $\mathrm{C}-\mathrm{C}$ bonds. The corresponding peak in GO-PCL in chloroform solution was observed around $450 \mathrm{~nm}$ (figure 3 (c), inset). The $\pi-\pi$ stacking forces created by the $\mathrm{sp}^{2}$ bonding and hydrophobic interaction between molecules allow graphene to be conducting $[21,91]$ which provides important cues for biocompatibility of GO and GO-PCL composites.

Wetting $\left(\mathrm{CA}_{\mathrm{w}}\right)$ and dewetting $\left(\mathrm{CA}_{\mathrm{dw}}\right) \mathrm{CAs}$ of thin GO sheet and GO-PCL mesh films are shown in figure S2(a) (supplementary information). In case of thin $\mathrm{GO}$ sheets, $\mathrm{CA}_{\mathrm{w}}$ was found to be around $\sim 58.7^{\circ}$ with hysteresis $\left(\mathrm{CA}_{\mathrm{w}}-\mathrm{CA}_{\mathrm{dw}}\right)$ of $\sim 4^{\circ}$ which might be a measure of the solid-liquid interaction [92]. For the GOPCL meshes, the CA was $\sim 75^{\circ}$. Due to the presence of GO with abundant hydroxyl group, CA of GO-PCL significantly $(p<0.05)$ decreased compared to PCL, $\left(\mathrm{CA} \sim 119^{\circ}\right)$. It is suggested that GO-PCL composite fibrous meshes could enhance cell adhesion as they are more hydrophilic and have higher surface energy due to the presence of GO. The stress-strain curves of GO sheets and GO-PCL meshes were shown in figure S2 (b) (supplementary information). The tensile strength of PCL ( 1.8 MPa) was found to increase significantly with addition of GO $(\sim 4.0 \mathrm{MPa})$, as shown in PCL (figure S2(b)). The tensile strength is also known to increase with increasing GO concentration [22]. Favourable CA and mechanical properties supported GO and GO-PCL meshes for TE applications.

\subsection{Myoblast differentiation, proliferation and myotubes formation}

Figure S3 (in supplementary information) schematically shows the complete cell culture process starting from CB-hMSCs isolation to myoblast differentiation of CB-hMSCs and aligned myotubes formation on the substrate. Figure 4 shows cells viability and myoblasts proliferation on GO sheets, GO-PCL mesh and controls. Cells viability (from WST-8 assay analysis) was found to increase significantly for GO sheets and GO-PCL meshes compared to the control surfaces ${ }^{*}$ : $p<0.05)$. This result implied that GO sheets and GOPCL meshes were cytocompatible and supported cell proliferation. FACS analysis of cells adhered on thin GO sheets and GO-PCL meshes was performed to confirm the positive expression of myogenic markers CD56 and desmin indicating skeletal muscle cell phenotype (figure 5). Myogenic markers were better expressed on GO-PCL meshes than that on the GO sheets indicating GO-PCL composite mesh as a better candidate for skeletal muscle tissue regeneration. As shown in fissure S4 (supplementary information), myogenic markers expressed better on collagen mesh compared to that on glass control.

Figures 6(a)-(d) depict the morphological analysis of adhered skeletal myoblasts differentiated from CBhMSCs on GO-PCL mesh, GO-sheets and controls, respectively. After 3 days of culture, the aspect ratios measured on GO-PCL meshes, GO sheets and the controls were found to be $\sim 6.6, \sim 5.4$ and $(\sim 4.7$ for collagen and $\sim 4.3$ for collagen coated glass), respectively, (figure 6(e)). Compared to GO sheets and controls, a more elongated bipolar morphology of skeletal myoblasts was observed on GO-PCL substrates. After 11 days of culture, FESEM analysis confirmed (figures $7(\mathrm{a})-(\mathrm{d})$ ) myoblast fusion and aligned myotubes formations on the fore substrates. Myotubes formed on GO sheets and GO-PCL meshes were 


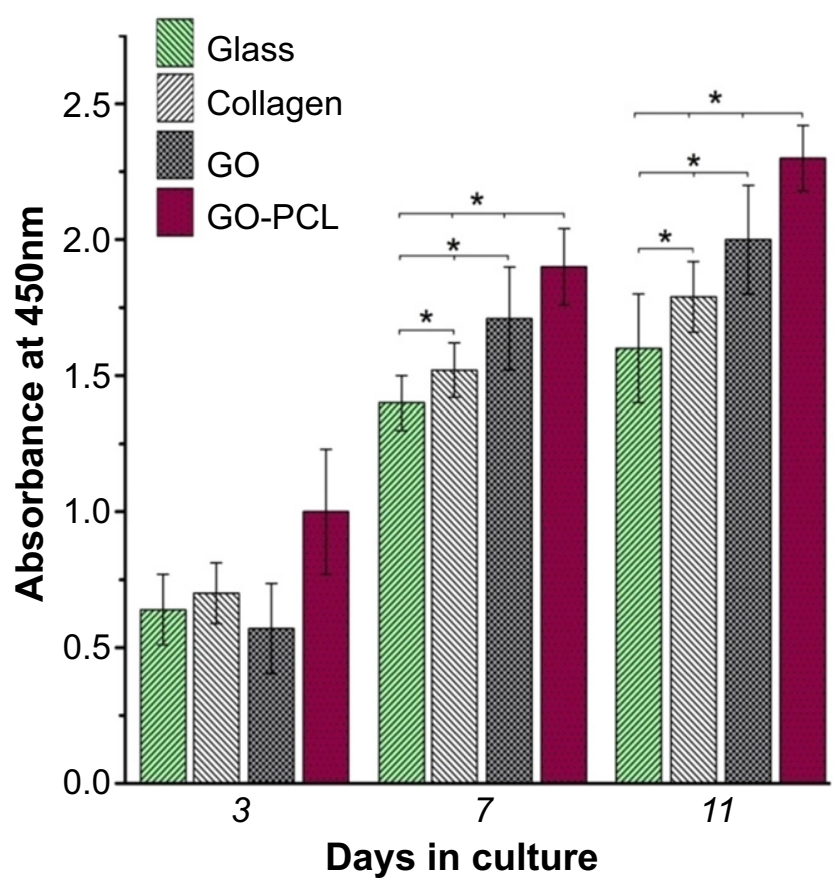

Figure 4. Cells viability and proliferation observed by tetrazolium salt (WST-8) assay (analysed by Graph pad Prism software and the results presented as the means \pm standard deviation $).{ }^{*}$ indicates significant difference $(n=5 ; p<0.05)$.
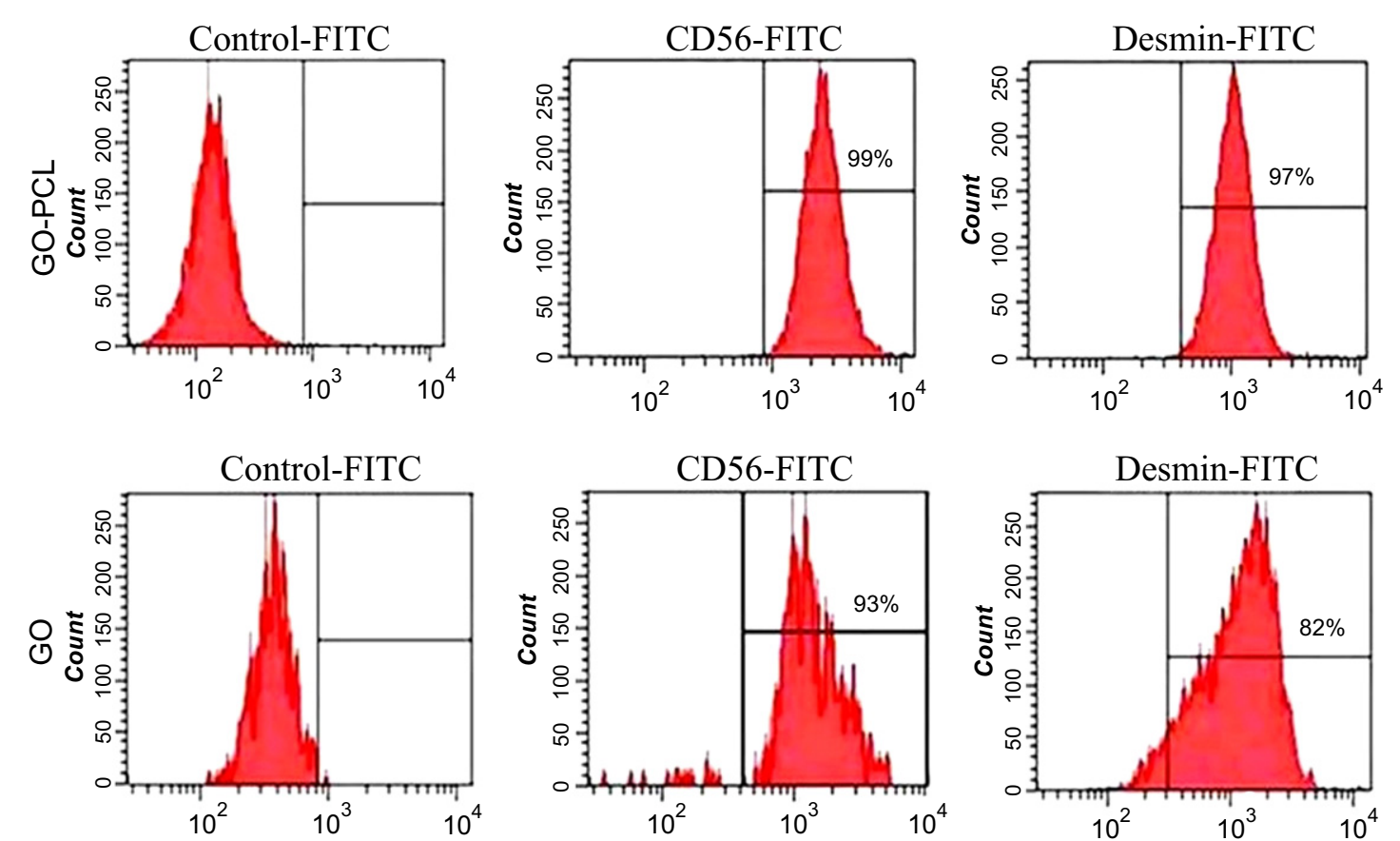

Figure 5. FACS analysis of trypsinized hSkMCs from GO-PCL meshes and GO sheets after 7 days of culture (cells highly expressed for skeletal muscle markers CD56 and desmin).

found to be more aligned compared to those on the control substrates. The density of aligned myotubes was also the highest on the GO-PCL meshes. The cell proliferation, differentiation and orientation onto GO sheets and GO-PCL meshes, confirmed their biocompatibility. A better biocompatibility of GO-PCL meshes might be associated with interconnectivity of fibrous meshes and enhanced $\sigma$ and $\varepsilon$ induced by GO, which might play an important role guiding cell adhesion, resulting in a higher proliferation and myotubes orientation.

Immunostaining also confirmed differentiation of CB-hMSCs to myoblasts via early expression of myogenin-positive nuclei on controls, GO sheet and GOPCL mesh (figures 7(e)-(h)). Quantitative analysis of the percentage of myogenin-positive nuclei showed 

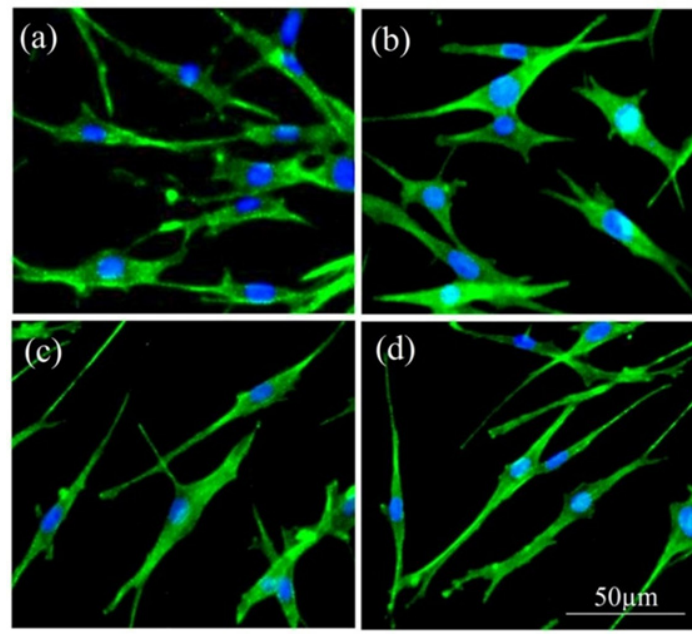

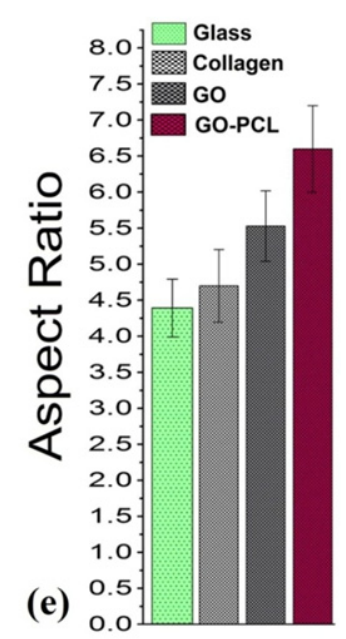

Figure 6. Analysis of cytoskeleton development of hSkMCs grown on (a) ECM coated glass, (b) collagen mesh, (c) GO sheets, (d) GOPCL meshes. (e) Cell aspect ratio quantification from (a)-(d) after 3 days of culture.

(figure S5 in supplementary information) that myogenin expression increased more on thin GO sheets and GO-PCL meshes compared to that on control substrates (collagen and glass), which also indicated a better differentiation potential of the GO-based substrates. Moreover, muscle specific antigens like MHC shown in figures 7(i)-(l) and dystrophin (figures $7(\mathrm{~m})-(\mathrm{p})$ ) were expressed more intensely on GO-PCL meshes compared to those on thin GO sheets or control substrates. Importantly, GO-PCL meshes also showed the highest percentage of myogenin positive nuclei ( $\sim 19 \%$ ) (figure $S 5$ in supplementary information).

\subsection{Conductivity $(\sigma)$, dielectric constant $(\varepsilon)$ and in vitro stability of thin GO sheet and GO-PCL meshes}

Admirable biocompatibility (cells adhesion, differentiation, proliferation and aligned myotubes formation) of GO sheets and GO-PCL meshes were found to be associated with their $\sigma$ and $\varepsilon$ values. Figures S6 and S7 (supplementary information) showed low RT $\sigma$ values $\left(\sim 10^{-7} \mathrm{~S} \mathrm{~m}^{-1}\right)$ and high values of $\varepsilon(\sim 900)$ for GO sheets which might be due to its high charge trap density $\left(\sim 1.2 \times 10^{18} \mathrm{~cm}^{-3} \mathrm{eV}^{-1}\right) \quad[44,62,63]$. GO conductivity appears through the $\mathrm{sp} 2$ regions via Klein tunnelling mechanism [89]. Figures S6 and S7 also showed an increase of both $\varepsilon$ ( $\sim 300$ for GO-PCL and only 25 for PCL) and $\sigma$ (more than two orders of magnitude higher in GO-PCL compared to that of PCL) for GO-PCL meshes, which was due to the presence of GO in PCL. Similar enhancement of $\sigma$ and $\varepsilon$ was also observed in GO-PVA and other GOpolymer composites $[9,52,93]$. It was reported that conductivity increment in GO-PMMA (poly-methacrylate), was due to deformed graphene nanosheets [93]. Enhancement of $\sigma$ and $\varepsilon$ in GO-PCL might be due to the formation of conducting pathways between the more conducting deformed GOnPs sheets (enhancing $\sigma$ ) and the creation of micro-capacitors with insulating PCL acting as dielectric films [53, 72, 94]. In GO sheets, a mixture of both positive and negative charges is present, which lead to a decrease of $\sigma$, but to an increases in polarizability (PE) and hence dielectric constant $[44,52]$. It is further noticed that both $\sigma$ and $\varepsilon$ values of GO sheets and GO-PCL meshes slightly decreased with increasing of immersion time in PBS indicating in vitro stability. Moreover, no significant morphological change of the GO sheets was observed as indicated by FESEM (figure S6). The addition of GO also reduced the degradation rate of GO-PCL (compared to PCL only), as revealed from the lower decreasing rates of $\sigma$ and $\varepsilon$ compared to those of PCL. Therefore, this study highlighted that both GO sheets and GO-PCL meshes could retain their $\sigma$ and $\varepsilon$ and hence stability over one week. The controllable enzymatic degradation of graphene/PCL materials was studied by Murry and collaborators [56] and these substrates were proved to be promising biodegradable electro-responsive scaffolds for skeletal muscle TE applications. Even the degradation products of the composite materials were reported [56] to exhibit less inhibition to cell metabolism and proliferation than the degradation products of pure PCL. Controllable non-toxic degradation and unique physical properties confirmed that covalently-linked PCL-graphene based composites are ideal materials for the development of electro-responsive scaffold for muscle TE.

It is evident from the above discussion that GO sheetsas well as its GO-polymer composites might be considered as a new class of biomaterials for implants, since $\mathrm{PE}$ and high dielectric polymers have been tested as implant that stimulate bone tissue growth [95]. Dielectric, PE and conductivity of different polymer and composite materials [6, 7, 96, 97] showed increased myoblast differentiation [6], enhancement 


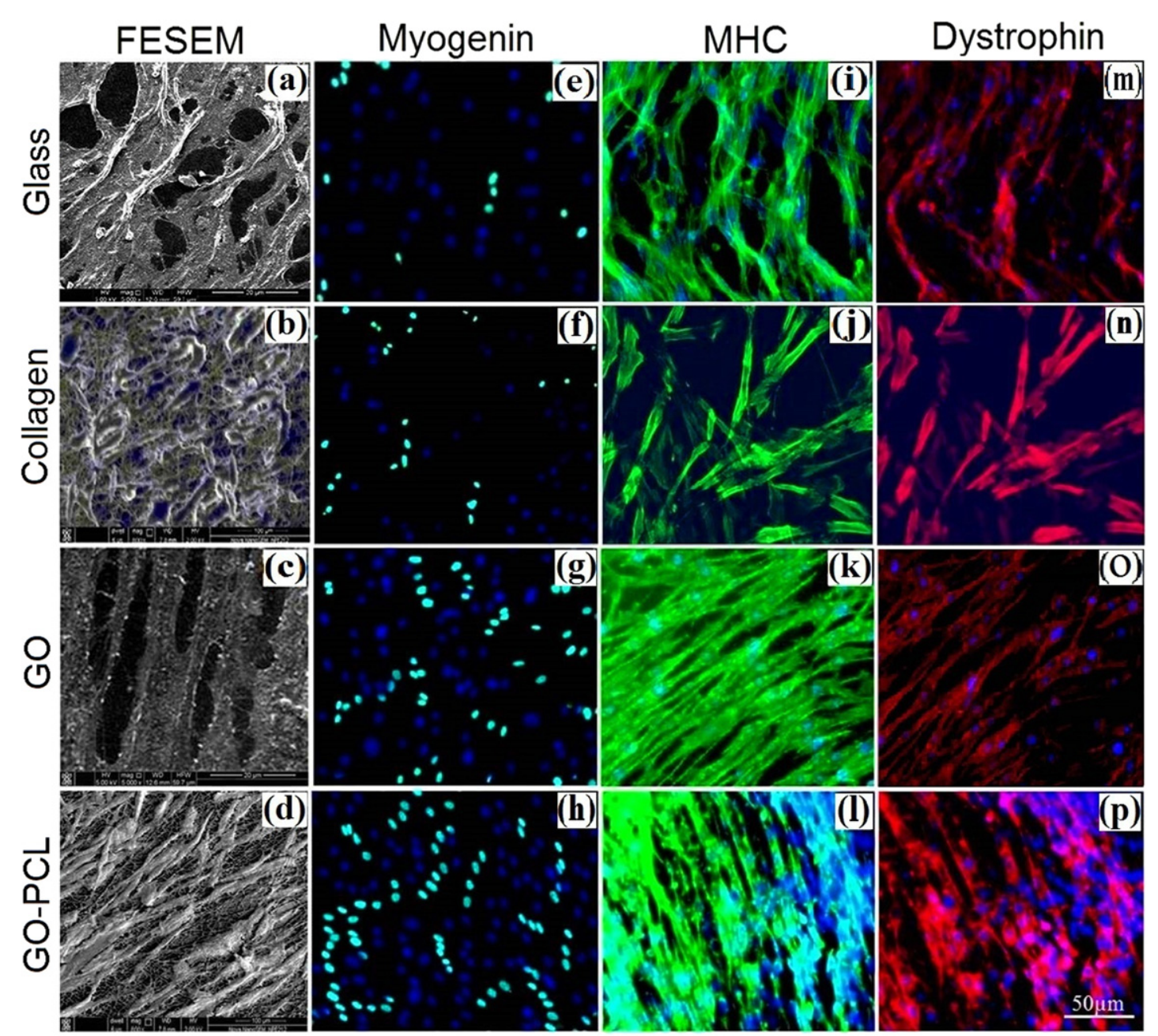

Figure 7. FESEM micrographs showing formation of myotubes on glass and collagen controls (a), (b), GO sheets (c) and GO-PCL meshes (d). Expression of the early myogenic differentiation marker myogenin-positive nuclei (green) on controls (e), (f), GO sheets (g) and GO-PCL meshes (h). Immunostaining of MHC (green), respectively, on controls (i), (j), GO sheets (k) and GO-PCL meshes (l) and dystrophin (red) similarly on controls (m), (n), GO sheets (o) and GO-PCL meshes (p). Nuclei were counterstained with DAPI.

of cardiac [27, 37] and neural [21] cells growth, as observed by different research groups. However, a biological mechanism upon which these physical properties of GO are related to biocompatibility is not very clear. It is known that during their proliferation, secrete various substances which are adsorbed ontothe graphene surface and effect cell proliferation [21, 92]. Conductivity of graphene and its derivatives depends on the $\mathrm{sp} 2$ hybridization process (contributions from sigma and $\pi$ bonds) [91]. The unique electrical and other properties of graphene are associated with the $\pi$ bonds. The $\pi$ electron-cloud in graphene interacts with the hydrophobic cores of proteins. Due to the presence of oxygenated groups, the hydrophilic GO can bind to serum proteins via electrostatic interaction which depends on conducting properties of GO. Moreover, the enzymatic degradation of graphene/ PCL materials might also provide important cues for biodegradable scaffolds for such electro-responsive tissue types [56]. The attractive $\pi-\pi$ staking forces are created by the consecutive sp2 bonding of graphene molecules and benzene rings possessed by some amino acids like, lysozyme, bone morphogenetic protein, trypsin, peptides or heparin were found to bind well on the GO and graphite surfaces [98-103]. The availability of $\pi$ electron cloud carried on graphene is proposed to interact with the hydrophobic protein, forming non covalent bond between them [97]. Thus the $\pi$ electrons which are associated directly or indirectly to the surface charge and other electrical properties of the GO based substrates might be primarily responsible for their cells-scaffold constructs which favor muscle or other tissues regeneration.

\section{Conclusion}

In this study, we demonstrated that thin GO sheets and GO-PCL nanofibrous meshes are biocompatible substrates excellent for hSkMCs differentiation of CBhMSCs. Myoblast differentiation capability of GO sheet was attributed to its surface change, and nano- 
structured surface morphology. In demand of cell specific substrates for the next generation of TE applications, the use of GO sheets and GO-based polymer composite meshes might be considered as most favourable candidates for skeletal muscle regeneration. Compared to GO, GO-PCL composite meshes showed better biocompatibility. Addition of GOnPs enhanced both conductivity and dielectric constant of GO-PCL meshes and provided supporting cues stimulating highly oriented multinucleated myotubes formation, similar to natural orientation, which is highly desirable for the regeneration of functional skeletal muscle. Moreover, the specific surface properties offered by GO-based biomaterials in combination with multipotent mesenchymal stem cells obtained from easily available UCB might be employed for the regeneration of other tissues.

\section{Acknowledgments}

Authors (BC and KP) are grateful to the Department of Biotechnology, Government of India, for providing fellowship to (BC) under the grant no DBT/1234/ 2010-2014. Authors are also grateful to, IACS, Kolkata, for providing SEM, TEM, and Raman facilities used for the present investigation.

\section{References}

[1] Bach A D, Beier J P, Staeter J and Horch R E 2004 Skeletal muscle tissue engineering J. Cell Mol. Med. 4 13-22

[2] Chen GP, Ushida T and Tateishi T 2002 Scaffold design for tissue engineering Macromol. Biosci. 2 67-77

[3] Sabir M L, Xu X and Li I 2009 A review of biodegradable polymeric materials for bone tissue engineering applications J. Mater. Sci. 44 5713-24

[4] Yan X, Chen J, Yang J, Xue Q and Miele P 2010 Fabrication of free-standing, electrochemically active, and biocompatible graphene oxide-polyaniline and graphene-polyaniline hybrid papers ACS Appl. Mater. Interfaces $92521-9$

[5] Baker S C, Rohman G, Southgate J and Cameron N R 2009 The relationship between the mechanical properties and cell behavior of PLGA and PCL scaffolds for blended tissue engineering Biomaterials 30 1321-6

[6] Wan C and Chen B 2011 Poly( $\varepsilon$-caprolactone)/graphene oxide biocomposites: mechanical properties and bioactivity Biomed. Mater. $6055010-8$

[7] Ravichandran R, Sundarrahjan S, Venugopal R J, Mukherjee S and Ramakrishna S 2010 Application of conducting polymers and their issues in biomedical engineering J. R. Soc. Interface 7 S559-79

[8] Chen M C, Sun Y C and Chen Y H 2013 Electrically conductive nanofibers with highly oriented structures and their potential application in skeletal muscle tissue engineering Acta Biomaterialia $95562-72$

[9] Kim H, Abdala A A and Macosko C W 2010 Graphene/ polymer nanocomposites Macromolecules 43 6515-30

[10] Markovic Z M, Harhaji-Trajkovic L M, Todorovic-Markovic B M, Kepić D P, Arsikin K M, Jovanović S P, Pantovic A C, Dramićanin M D and Trajkovic V S 2011 In vitro comparison of the photothermal anticancer activity of graphene nanoparticles and carbon nanotubes Biomaterials 32 1121-9

[11] Choi J S, Lee S J, Christ G J, Atala A and Yoo J J 2008 Influence of electrospun aligned poly (e-caprolactone)/collagen nanofiber meshes on the formation of self-aligned skeletal muscle myotubes Biomaterials 29 2899-906

[12] Sebaa M, Nguyen T Y, Paul R K, Mulchandani A and Liu H 2013 Graphene and carbon nanotube-graphene hybrid nanomaterials for human embryonic stem cell culture Mater. Lett. 92 122-5

[13] Kolbacova M, Broz A, Kong J and Kalbac M 2010 Graphene substrates promote adherence of human osteoblasts and mesenchymal stomalcells Carbon 48 4323-9

[14] Hu H, Ni Y, Montana V, Haddon R C and Parpura V 2004 Chemically functionalized carbon nanotubes as substrates for neuronal growth Nano Lett. 4507-11

[15] Malarkey E B, Fisher A K, Bekyarova E, Liu W, Haddon R C and Parpura V 2009 Conductive single walled carbon nanotubes modulate neural growth Nano Lett. 9 264-8

[16] Wang K, Ruan J, Song H, Zhang J and Cui D 2011 Biocompatibility of graphene oxide Nanoscale Res. Lett. 68

[17] Bonaccorsa F, Sun Z, Hasan T and Ferrari A C 2010 Graphene photonics and optoelectronics Nat. Photonics 4 611-22

[18] Liu Y, Yu D, Zhang C, Miao Z and Dai L 2010 Biocompatible graphene oxide based glucose biosensor Langmuir 26 6158-60

[19] Sanigrahi J, Bhadra D and Chaudhuri B K 2012 Crystalline graphite oxide/PVDF nanocomposite gate dielectric: lowvoltage and high field effect mobility thin-film transistor Phys. Status Solidi210 546-52

[20] Gaharwar A K, Peppas N A and Khademhosseini A 2014 Nanocomposite hydrogels for biomedical applications Biotechnol. Bioeng. $111441-53$

[21] Ryu S and Kim B S 2013 Culture of neural cells and stem cells on graphene Tissue Eng. Regenerative Med. 10 39-46

[22] Ku S H and Park C B 1913 Myoblast differentiation on graphene oxide Biomaterials 34 2017-23

[23] Akhavan O and Ghaderi E 2013 Graphene nanomesh promises extremely efficient in vivo photothermal therapy Small 93593-601

[24] Akhavan O, Ghaderi E and Shahsavar M 2013 Graphene nanogrids for selective and fast osteogenic differentiation of human mesenchymal stem cells Carbon 59 200-2211

[25] Zhang L M, Xia J G, Zhao Q H, Liu L W and Zhang Z J 2010 Functional graphene oxide as a nanocarrior for controlling loading and targeted delivery of mixed anticancer drugs Small 6537-44

[26] Goenka S, Sant V and Sant S 2014 Graphene-based nanomaterials for drug delivery and tissue engineering J. Control. Release 173 75-88

[27] Paul A et al 2014 Injectable graphene oxide/hydrogel-based angiogenic gene delivery system for vasculogenesis and cardiac repair ACS Nano 8 8050-62

[28] Hu W, Peng C, Luo W, Lv M, Li X, Li D, Huang Q and Fan C 2010 Graphene-based antibacterial paper ACS Nano 4 317-23

[29] Seabra A B, Paula A J, Lima R D, Alves O L and Duran N 2014 Nanotoxicity of graphene and graphene oxide Chem. Res. Toxicol. 27 159-68

[30] Song Q, Jian Z, Li N, Liu P, Liu L, Tang M and Cheng G 2014 Anti-inflammatory effects of three dimensional graphene foams cultured with microglial cells Biomaterials 35 6930-40

[31] Talukdar Y, Rashkow J, Lalwani G, Kanakia S and Sitharaman B 2014 The effect of graphene oxide nanostructure in mesenchymal stem cells Biomaterials 35 4863-77

[32] Chen GY, Pang D W, Hwang S M, Tuan HY and Hu Y C 2012 A graphene-based platform for induced pluripotent stem cells culture and differentiation Biomaterials 33 418-27

[33] Nayak T R et al 2011 Graphene for controlled and accelerated osteogenic differentiation of human mesenchymal stem cells ACS Nano 5 4670-8

[34] Yang X, Li L, Shang S and Tao X 2010 Synthesis and characterization of layer-aligned poly(vinylalcohol)/graphene nanocomposites Polymer 51 3431-5

[35] Dikin D A, Stankovich S, Zimneym E J, Pinerm R D, Dommettmm G H B, Evmenenkom G, Nguyenm S T and 
Ruoff R S 2007 Preparation and characterization of graphene oxide paper Nat. Lett. 448 457-60

[36] Fukada E and Yasuda I J 1957 On the piezoelectric effect of silk fibers J. Phys. Soc. Japan 121158

[37] Kai D, Prabhakaran M and Jain Gand Ramakrishna S 2013 Biocompatibility evaluation of electrically conductive nanofibrous scaffolds for cardiac tissue engineering J. Mater. Chem. B $12305-13$

[38] Li N, Zhang X, Song Q, Su R, Zhang Q, Kong T, Liu L, Jin G, Tang M and Cheng G 2011 The promotion of neurite sprouting and outgrowth of mouse hippocampal cells in culture by graphene substrate Biomaterials 32 9374-82

[39] Jun I, Jeong S and Shin H 2009 The stimulation of myoblast differentiation by electrically conductive sub-micron fibers Biomaterials 30 2038-47

[40] Shao S, Zhiu S, Li L, Li J, Luo C, Wang J, Li X and Weng J 2011 Osteoblast function on electrically conductive electrospun PLA/MWCNTs nanofibers Biomaterials 32 2821-33

[41] Marino AA, Rosson J, Gonzalez E, Jones L, Rogers S and Fukada E 1988 Quasi-static charge interactions in bone J. Electrost. $21347-460$

[42] Takeda H, Nakamura S, Yamada K, Tsuchiya T and Yamadshita K 2000 Dielectric properties of poled hydroxyapatite ceramics Key Eng. Mater. 181-2 35-8

43] Fukada E 1995 Piezielectricity and Pyroelectricity of Biopolymers, Ferroelectric Polymers ed H S Nalwa (New York: Dekker) pp 393-439

[44] Nakamura S, Kobayashi T and Yamashita K 2001 Enhanced osteobonding by negative surface charge of electrically polarized Hydroxyapatite J. Biomed. Meter. Res. 57 477-84

[45] Lima C G A, de Oliveira R S, Figueiro S D, Wehmann C F, Goes J C and Sombra A S B 2006 DC conductivity and dielectric permittivity of collagen chitosan films Mater. Chem. Phys. 99 284-8

[46] Mozafari M, Mehraien M, Vashaee D and Tayebi L 2012 Electroconducting nanocomposite scaffold: a new strategy into tissue engineering and regenerative medicine Nanocomposites - New Trend and Development ed F Ebrahimi (USA: In Tech) IBSN 978-953-51-07620

[47] Rivers T J, Hudson T W and Schmidt C E 2002 Synthesis of a novel, biodegradable electrically conducting polymer for biomedical applications Adv. Funct. Mater. 12 33-7

[48] Drvir T, Timko B P, Brigham M D, Naik S R K, Levy O, Jin W D, Parker K K, Langer R and Kohane D S 2011 Nanowired three-dimensional cardiac patches Nat. Nanotechnology Lett. $6720-5$

[49] Hardy J G and Schmidt E E 2013 Biomimetic conducting polymer based tissue scaffolds Curr. Opin. Biotechnol. 24 847-54

[50] Wallace G G, Higgins M J, Mouton S E and Wang C 2012 Nanobionics: impact of nanotechnology on implantable bionic devices Nanoscale 4 4327-47

[51] Syyar S, Murray E, Thompson B C, Gambhir S, Officer D L and Wallace G G 2013 Covalently linked biocompatibile graphene/policaprolactone composite for tissue engineering Carbon 52 296-304

[52] Bhadra D, Sannigrahi J, Chaudhuri B K and Sakata H 2012 Enhancement of the transport and dielectric properties of graphite oxide nanoparticles-polyvinyl alcohol composite showing low percolation threshold Polym. Compos. 33 436-42

[53] Ansari S and Giannelis E P 2009 Functionalized graphene sheet-poly(vinylidene fluoride) conductive nanocomposites J. Polym. Sci. B 47 888-97

[54] Zhang H et al 2013 Uniform ultra-small graphene oxide nanosheets with low cytotoxicity and high cellular uptake ACS Appl. Mater. Interface 5 1761-7

[55] Yang K, Wan J M, Zhang S A, Zhang Y J, Lee S T and Liu Z A 2011 Long term biodistribution and toxicology of pegylated graphene in mice Parmacokinetic vivo, editor ACS Nano 5 516-44

[56] Murry E, Thomson B C, Sayyar S and Wallace G 2015 Enzymatic degradation of graphene/polycaprolactone materials for tissue engineering Poym. Degradation Sability 111 71-7

[57] Taravel M N and Doamrd A 1995 Collagen and its interaction with chitosan:II. Influence of physicochemical characteristics of collagen Biomaterials 16 865-87

[58] Sousa V O S, Silva C C, Almeida A F L, Fifueiro S D, Goes J C, de Paiva J A C, Magalhaes C E C and Sombra A S B 2002 Study of the electrical conductivity and piezoelectricity in iron doped collagen films Solid State Sci. 4 43-51

[59] Bowen C R, Gittings J and Turner I G 2006 Dielectric and piezoelectric properties of hydroxyapatite- $\mathrm{BaTiO}_{3}$ composites Appl. Phys. Lett. 89 132906-3

[60] Gittings J P, Browen C R, Turner I G, Baxter F and Chaudhuri J 2007 Characterization of ferroelectric-calcium phosphate composites and ceramics J. Eur. Ceram. Soc. 27 4187-490

[61] Wang S, Ang P K, Wang Z, Tang A L L, Thong J T L and Loh K P 2010 High mobility, printable and solution processed graphene electronics Nano Lett. $1092-8$

[62] Li J L, Kudin K N, McAllister M J, Prudhomme R K, Aksay I A and Car R 2006 Oxygen-driven unzipping of graphitic materials Phys. Rev. Lett. 96 176101-4

[63] Chang Z, Yan W, Shang J and Liu J 2014 Piezoelectric properties of graphene oxide: a computational study Appl. Phys. Lett. 105 023103-5

[64] Bendrea A D, Cianga L and Cinga I 2011 Review paper: progress in the field of conducting polymers for tissue engineering applications J. Biomater. Appl. 26 3-84

[65] Line M E and Glass A M 2001 Principles and Applications of Ferroelectric and Related Materials (Oxford: Oxford University Press) ISBN: 9780198507789

[66] Mascarenhas S 1987 Bioelectrets in topics Applied Physics Electrets vol 23 (Berlin: Springer)

[67] Herbst E 1978 Electrical Stimulation of Bone Growth and Repair ed F Burny, E Herbst and M Hinsonkamp (Berlin: Springer) pp 1-13

[68] Gaharwar A K, Mukundan S, Karaca E, Dolatshahi-Pirouz A Patel A, Rangarajan K, Mihaila S M, Iviglia G, Zhang H and Khademhosseini A 2014 Nanoclay-enriched poly(e-caprolactone) electrospun scaffolds for osteogenic differentiation of human mesenchymal stem cells Tissue Eng. A 15-162088-101

[69] Biosoyi A, Pramanik K, Panda N N and Sarangi S K 2014 Cryopreservation of hMSCs seeded silk nanofibers base tissue engineered constructs Cryobiology 68 132-42

[70] Akhavan O, Ghaderi E and Akhavan A 2012 Size-dependent genotoxicity of graphene nanoplatelets in human stem cells Biomaterials 33 8017-25

[71] Hummers W S and Offeman RE 1958 Preparation of Graphene oxide J. Am. Chem. Soc. 80 1339-43

[72] Uddin M J, Sanigrahi J, Masud M G, Bhadra D and Chaudhuri B K 2012 High dielectric permittivity and percolative behaviour of polyvinyl alcohol and/potassium dihydrogenphophote composites J. Appl. Polym. Sci. 125 2363-6

[73] Chaudhuri B and Pramanik K 2013 Isolation of mononuclear stem cells from human umbilical cord blood and study of cell scaffold interaction Adv. Sci. Eng. Med. 5 427-30

[74] Jiang S, Xiangling J I, Lijia A and Jiang B 2011 Crystallization behaviour of PCL in hybrid confined environment Polymer 423901-7

[75] Du X S, Xiao M, Meng Y Z and Hay A S 2005 Direct synthesis of poly(acrylenedisulfide)/carbon nanosheet composites via the oxidation with graphite oxide Carbon 43 195-213

[76] Chen W, Yan I and Bangal P R 2010 Preparation of graphene by rapid and mild graphene oxide by microwave Carbon 48 1146-52

[77] Schniepp H C, Li J L, McAllister M J, Sai H, Herrera-Alonso M, Adamson D H, Prudhomme R K, Car R, Savie D A and Aksay I A 2006 Functionalized sing graphene sheets derived from splitting graphite oxide J. Phys. Chem. B $1108535-9$

[78] Tuinstra F and Koening J L 1970 Characterization of graphite fibre surfaces with Raman spectroscopy Compos. Mater. 4 492-9 
[79] Jung I, Dikin D A, Piner R D and Ruoff R S 2008 Tunable electrical conductivity of individual graphene oxide sheets reduced at 'low' temperatures Nano Lett. 84283-7

[80] Eda G, Mattevi C, Yamaguchi H, Kim H and Chhowalla M 2009 Insulator to semimetal transition in graphene oxide J. Phys. Chem. C 113 15768-71

[81] Ferrari A C et al 2006 Romon spectrum of graphene and graphene layers Phys. Rev. Lett. 97 187401-4

[82] Kim K S, Zhao Y, Jang H, Lee SY, Kim J M, Kim K S, Ahan J H, Kim P, Choi Y and Hong B H 2009 Large-scale pattern growth of graphene films for stretchable transparent electrodes Nature 457 706-710

[83] Calizo I, Balandin A A, Bao W, Miao F and Lau C N 2007 Temperature dependence of Raman spectra of graphene and graphite multilayers Nano Lett. 7 2645-9

[84] Kudin K N, Ozbas B, Schniepp H C, Prud'homme R K, Aksay I A and Car R 2008 Raman spectra of graphite oxide and functionalized graphene sheets Nano Lett. 836-41

[85] Shang J, Ma L, Li J, Ai W, Ting Y T and Gurzadyan G G 2012 The origin of fluorescence from grapheme oxide Sci. Rep. 2792

[86] Marcano D C, Kosynkin D V, Berlin J M, Sinitskii A, Sun Z, Slesarev A, Alemany L B, Lu W and Tour J M 2010 Improved synthesis of graphene oxide ACS Nano 4 4806-14

[87] Mattevi C, Eda G, Agnoli S, Miller S, Mkhoyan K A, Celik O, Mastrogiovanni D, Granozzi G, Garfunkel E and Chowalla M 2009 Evolution of electrical, chemical, and structural properties of transparent and conducting chemically derived graphene thin films Adv. Funct. Mater. 192 577-2583

[88] Xu J, Liu J, Wu S, Yang Q H and Wang P 2012 Graphene oxide mode-locked femptosecond erbium doped fiber lasers Opt. Express 20 15474-80

[89] Katsnelson M I, Novoselov K S and Geim A K 2006 Chira tunnelling and Klein paradox in graphene Nat. Phys. 2 $620-5$

[90] Shimanouchi T 1972 Tables of molecular vibrational frequencies J. Phys. Chem. Ref. Data 1 189-216

[91] Lee W C, Lim C H, Shi H, Tang L A, Wang Y, Lim C T and Loh K P 2011 Origin of enhanced stem cells growth and differentiation on graphene and graphene oxide ACS Nano 5 7334-41
[92] Lee S J, Khang G, Lee Y M and Lee H B 2003 The effect of surface wettability on induction and growth of neurites from PC-12 cell on a polymer surface Colloid Interface Sci. 259 228-35

[93] Goncaves G, Marques P A A, Timmons A B, Badkin I, Singh M K, Emamis N and Gracis J 2010 Graphene oxide modified with PMMA via ATRP as a reinforced filler J. Mater. Chem. 20 9927-34

[94] Uddin M J, Masud M G, Ghosh A, Middya T R and Chaudhuri B K 2013 Ammonium dihydrogen phosphate/ PVA composite films with high dielectric constant and enhanced thermal stability Adv. Sci. Eng. Med. 5 126-5

[95] Fukuda E 1981 Piezoelectric of bone and osteogenesis by piezoelectric films Mechanisms of Growth Control ed R O Becker (Springfield, 1L: Charles C Thomas) pp 192

[96] Seil J T and Webster T J 2010 Electrically active nanomaterials as improved neural tissue regeneration scaffolds Nanomed. Nanobiotechnology 2635-47

[97] Liao I C, Liu J B, Bursac N and Leong K W 2008 Effect of electromechanical stimulation on the maturation of myotubes on aligned electrospun fibers Cell. Mol. Bioeng. 133-45

[98] Wheeler S E 2013 Understanding substituent effects in noncovalent interactions involving aromatic rings Acc. Chem. Res. 16 1029-38

[99] Utesch T, Gaminelli G and Mroginski M A 2011 Molecular dynamics simulations of the adsorption of bone morphogenetic protein- 2 on surface with medicalrelevance Langmuir 27 13144-53

[100] Mucksch C and Urbassek H M 2011 adsorption of BMP-2 on a hydrophobic graphite surface: a molecular dynamics study Chem. Phys. Lett. 510 252-6

[101] Xu G, Chen X, Hu J, Yang P, Yang D and Wei L 2012 Immobilization of trypsin on grapheme oxide for microwave-assisted on-plane proteolysis combined with MALDIMS analysis Analyst 137 2757-61

[102] Sheng Y, Wang W and Chen P 2010 Interaction of an ionic complementary peptide with a hydrophobic graphite surface Protein Sci. 19 1639-48

[103] Lee D Y, Khatun Z, Lee J H, Lee Y and In I 2011 Blood compatible graphene heparin conjugate through monovalent chemistry Biomacromolecules 12 336-41 